\title{
Engineering of Saccharomyces cerevisiae for the production of poly-3-D-hydroxybutyrate from xylose
}

\author{
Anders G Sandström, Alejandro Muñoz de las Heras, Diogo Portugal-Nunes and Marie F Gorwa-Grauslund
}

\begin{abstract}
Poly-3-D-hydroxybutyrate (PHB) is a promising biopolymer naturally produced by several bacterial species. In the present study, the robust baker's yeast Saccharomyces cerevisiae was engineered to produce PHB from xylose, the main pentose found in lignocellulosic biomass. The PHB pathway genes from the well-characterized PHB producer Cupriavidus necator were introduced in recombinant $S$. cerevisiae strains already capable of pentose utilization by introduction of the fungal genes for xylose utilization from the yeast Scheffersomyces stipitis. PHB production from xylose was successfully demonstrated in shake-flasks experiments, with PHB yield of $1.17 \pm 0.18 \mathrm{mg} \mathrm{PHB} \mathrm{g}{ }^{-1}$ xylose. Under well-controlled fully aerobic conditions, a titer of $101.7 \mathrm{mg} \mathrm{PHB} \mathrm{L}^{-1}$ was reached within 48 hours, with a PHB yield of $1.99 \pm 0.15 \mathrm{mg} \mathrm{PHB} \mathrm{g}^{-1}$ xylose, thereby demonstrating the potential of this host for PHB production from lignocellulose.
\end{abstract}

Keywords: Polyhydroxyalkanoate; PHB; Xylose; Saccharomyces cerevisiae; Metabolic engineering; Biopolymer

\section{Introduction}

Petroleum-based plastics are essential elements of our contemporary society, and will remain so for a foreseeable future. Still, the world is standing at the threshold of an era marked by scarce fossil-based resources (Lambert et al. 2014; Foley et al. 2011), which called for a transition towards the production of bio-based bulk chemicals from renewable feedstock (European Parliament CotEU 2009). Among candidate feedstock for bio-based polymer production, lignocellulosic biomass such as corn stover, wheat straw or sugar cane bagasse, are amongst the most promising ones (Gírio et al. 2010). Another readily available lignocellulosic feedstock is the spent sulfite liquor (SSL), one of the main by-products from the pulp and paper industry (Novy et al. 2013).

However, up to now, the bio-based polymers that are entering the market as replacement for their petroleumbased counterparts are produced from simple sugars, such as glucose, or food crop residuals such as glycerol. Polyhydroxyalkanoates (PHAs) are some of the most promising biodegradable biopolymers for a sustainable

\footnotetext{
* Correspondence: Marie-Francoise.Gorwa@tmb.lth.se

Division of Applied Microbiology, Department of Chemistry, Lund University, PO Box 124, Lund SE-221 00, Sweden
}

future (Philip et al. 2007). Poly-(R)-3-hydroxybutyrate (PHB), that is naturally produced by several bacterial species as an energy storage depot, typically under conditions of nitrogen starvation (Suriyamongkol et al. 2007; Madison and Huisman 1999), is one of the most studied PHAs. Numerous hosts have been suggested as PHA producers, such as natural PHB-producing bacterial species or engineered Escherichia coli. Nevertheless $E$. coli suffers from regular phage infections in industrial production settings (Lian et al. 2014), while the natural PHB-producing bacterial species are not well adapted to harsh environments, such as growth in SSL. Instead baker's yeast Saccharomyces cerevisiae, that is known for its tolerance to acidic and inhibitor-rich conditions, is considered one of the favored species for converting the sugars found in SSL into bulk chemicals of interest - e.g. PHB (Demeke et al. 2013). SSLs are commonly rich in xylose, a pentose sugar that is not naturally consumed by $S$. cerevisiae. Therefore, efficient xylose-metabolizing S. cerevisiae strains have been developed (Hahn-Hägerdal et al. 2007; Kim et al. 2013).

The potential of engineered $S$. cerevisiae as a producer of PHAs from pure hexose sugars has previously been 
explored by several groups. First, only the polyhydroxyalkanoate synthase gene from the PHB producer Cupriavidus necator (formerly known as Ralstonia eutropha (Vandamme and Coenye 2004)) was overexpressed (Leaf et al. 1996) and PHB was produced by the available cytosolic 3-hydroxybutyryl-CoA, derived from the fatty acid $\beta$-oxidation pathway. Several strategies aiming at increasing the available pool of precursors have been tested in S. cerevisiae in order to increase the yield of PHB, for example addition of the C. necator $\beta$ ketothiolase and acetoacetyl-CoA reductase genes (Carlson and Srienc 2006; Breuer et al. 2002), enzymes for boosting ethanol assimilation and acetyl-CoA synthesis (Kocharin et al. 2012) and addition of the phosphoketolase pathway and non-phosphorylating $\mathrm{NADP}^{+}$-dependent glyceraldehyde3-phosphate dehydrogenase for increasing the NADPH pool (Kocharin et al. 2013). Here, we demonstrate that S. cerevisiae can also be engineered to produce $\mathrm{PHB}$ from D-xylose.

\section{Materials and methods}

\section{Strains, media and culture conditions}

Plasmids and yeast strains used in this study are listed in Table 1. E. coli strain NEB5- $\alpha$ (New England Biolabs) was used for sub-cloning of plasmid DNA and further propagation. Lysogeny broth (LB) $\left(5 \mathrm{~g} \mathrm{~L}^{-1}\right.$ yeast extract, $10 \mathrm{~g} \mathrm{~L}^{-1}$ peptone, $5 \mathrm{~g} \mathrm{~L}^{-1} \mathrm{NaCl}, \mathrm{pH}$ 7.0) medium was used for routine culturing of E. coli and $50 \mathrm{mg} \mathrm{L}^{-1}$ ampicillin was added to LB when needed. Bacterial transformants were selected on solid LB plates ( $15 \mathrm{~g} \mathrm{~L}^{-1}$ agar), supplemented with ampicillin $\left(50 \mathrm{mg} \mathrm{L}^{-1}\right)$, for $16 \mathrm{~h}$ at $37^{\circ} \mathrm{C}$. Cultures of vector-carrying $E$. coli were recovered from $25 \%$ glycerol stocks stored at $-80^{\circ} \mathrm{C}$ and grown in liquid LB medium, supplemented with ampicillin, for $14-16 \mathrm{~h}$ at $37^{\circ} \mathrm{C}$ and $180 \mathrm{rpm}$ in an orbital shaker.

Yeast strains were recovered from 20\% glycerol stocks stored at $-80^{\circ} \mathrm{C}$, by streaking on solid YPD plates $\left(10 \mathrm{~g} \mathrm{~L}^{-1}\right.$ yeast extract, $20 \mathrm{~g} \mathrm{~L}^{-1}$ peptone, $20 \mathrm{~g} \mathrm{~L}^{-1}$ glucose, $15 \mathrm{~g} \mathrm{~L}^{-1}$ agar) for two days at $30^{\circ} \mathrm{C}$. Yeast cultures were grown in liquid YPD when preparing the strain for transformation for 14-16 h, or less when required, at $30^{\circ} \mathrm{C}$ and $180 \mathrm{rpm}$ in an orbital shaker.

Engineered yeast strains were selected on solid YNB medium (6.7 $\mathrm{g} \mathrm{L}^{-1}$ Yeast Nitrogen Base without amino acids (Becton, Dickinson and Company, USA) supplemented with $20 \mathrm{~g} \mathrm{~L}^{-1}$ glucose or xylose and $15 \mathrm{~g} \mathrm{~L}^{-1}$ agar). Leucine was added for complementation at a concentration of $30 \mathrm{mg} \mathrm{L}^{-1}$ when required.

All chemicals were purchased from Sigma-Aldrich if not otherwise stated.

\section{PHB pathway expression vector construction}

The PHB pathway genes PhaA, PhaBl, and PhaC1 from C. necator (Poehlein et al. 2011) were codon optimized towards S. cerevisiae and synthesized (Eurofins Genomics, Germany). The codon-optimized genes have been deposited with following accession numbers; PhaA [GenBank: KP681582], PhaB1 [GenBank:KP681583], PhaC1 [GenBank: KP681584]. The three coding regions were inserted inbetween the strong constitutive promoter-terminator pairs of the genes TEF1, TPI1, GPM1 (Sun et al. 2012), respectively. The promoters and terminators were amplified directly from the genome of S. cerevisiae CEN.PK113-7D (Nijkamp et al. 2012), and the PHB pathway genes were amplified by PCR from respective vector. The fragments were amplified with Phusion Hotstart II polymerase (Thermo Scientific, USA) using the following PCR program: initial denaturation at $98^{\circ} \mathrm{C}$ for $30 \mathrm{~s}, 30$ cycles of denaturation at $98^{\circ} \mathrm{C}$ for $10 \mathrm{~s}$, annealing at $65^{\circ} \mathrm{C}\left(-0.5^{\circ} \mathrm{C}\right.$ cycle $)$ for $30 \mathrm{~s}$ and elongation at $72^{\circ} \mathrm{C}$ for $15 \mathrm{~s}$ or $1 \mathrm{~min}$, and a final elongation step for $10 \mathrm{~min}$ at $72^{\circ} \mathrm{C}$. The three purified promoter, coding sequence and terminator fragments were assembled by overlap extension PCR (OE-PCR). Equimolar fragment amount were mixed, and the following overlap-extension program was used; $98^{\circ} \mathrm{C}$ for $30 \mathrm{~s}$, then 16 cycles at $98^{\circ} \mathrm{C}$ for $10 \mathrm{~s}, 68^{\circ} \mathrm{C}\left(-0.5^{\circ} \mathrm{C} /\right.$ cycle $)$ for $30 \mathrm{~s}, 72^{\circ} \mathrm{C}$ for $1 \mathrm{~min}$ and then hold at $12^{\circ} \mathrm{C}$ for the addition of amplification primers ( $50 \mu \mathrm{M}$ each), whereafter the program continued at $98^{\circ} \mathrm{C}$ for $30 \mathrm{~s}$, then 20 cycles at $98^{\circ} \mathrm{C}$

Table 1 Plasmids and strains used in this study

\begin{tabular}{lll}
\hline Plasmids & Relevant genotype & Reference \\
\hline Ylplac128 & LEU2 & (Gietz and Akio 1988) \\
YlpOB8 & PTDH3-XYL1-tADH1; pPGK1-XYL2-tPGK1; URA3 & (Runquist et al. 2010) \\
YlpAGS2 & Ylplac128; pTEF1-PhaA-tTEF1; pGPM1-PhaB1-pGPM1; pTP11-PhaC1-tTP11; LEU2 & This study \\
Yeast strains & Relevant genotype & Reference \\
\hline TMB 3043 & CEN.PK2-1C; gre34; his3::pPGK1-XKS1-tPGK1, HIS3; tal1::pPGK1-TAL1-tPGK1; & (Karhumaa et al. 2005) \\
TK11::pPGK1-TKL1-tPGK1; rki1::PPGK1-RKI1-tPGK1; rpe1:pPGK1-RPE1-tPGK1; ura3, leu2 & This study \\
TMB 4440 4443 & TMB 3043; ura3::YlpOB8; leu2 & This study \\
TMB 4444 & TMB 4440; leu2::YlpAGS2 & This study \\
\hline
\end{tabular}


for $30 \mathrm{~s}, 68^{\circ} \mathrm{C}\left(-0.5^{\circ} \mathrm{C} /\right.$ cycle $)$ for $30 \mathrm{~s}, 72^{\circ} \mathrm{C}$ for $1 \mathrm{~min}$, and then a final elongation at $72^{\circ} \mathrm{C}$ for $10 \mathrm{~min}$. The primers were designed such that the flanking ends of the generated fragments overlapped with the neighboring regions, enabling the use of In-Fusion cloning (Clontech, Takara-Bio, Japan). Linear vector fragments of YIplac128 (Gietz and Akio 1988) were generated by double-digestion with Fast Digest CfroI (XmaI) and SspDI (KasI) (Thermo Scientific, USA). The digested vector, and the three promotergene-teminator fragments were mixed in equimolar amounts and were assembled by In-Fusion cloning, according to the supplier's instruction. High efficiency competent NEB5- $\alpha$ cells were transformed according to the supplier's instructions. Plasmids were propagated, a diagnostic restriction digestion was performed and the cloned region was fully sequenced. The oligonucleotides used for the PCRs are listed in Table 2.

\section{Yeast strain engineering}

S. cerevisiae TMB 3043 (Karhumaa et al. 2005) was transformed with the EcoRV-linearized vector YIpOB8 (Runquist et al. 2010), generating the strain TMB 4440. The yeast cells were transformed using the highefficiency Li-Ac method (Gietz and Schiestl 2007), and plated on YNB-xylose $\left(20 \mathrm{~g} \mathrm{~L}^{-1}\right)$-plates, supplemented with leucine $\left(30 \mathrm{mg} \mathrm{L}^{-1}\right)$. The strain was subsequently transformed with Eco9I-linearized YIpAGS2 or YIp128 - to form the PHB-producing strain TMB 4443 or the corresponding control strain TMB 4444 (Table 1). Transformed strains were validated by amplifying stretches of the integrated cassette by PCR, using extracted genomic DNA as template and primers found in Table 2.

\section{Aerobic cultivations}

For the shake flasks experiments, well-aerated baffled shake flasks were used. Pre-cultures were started by transferring an isolated colony into $5.0 \mathrm{~mL}$ of defined buffered YNB-xylose (13.4 $\mathrm{g} \mathrm{L}^{-1}$ Yeast nitrogen base, $50 \mathrm{~g} \mathrm{~L}^{-1}$ xylose, $50 \mathrm{mM}$ potassium hydrogen phthalate, $\mathrm{pH} 5.5)$ in $50 \mathrm{~mL}$ conical centrifuge tube, shaking at $30^{\circ} \mathrm{C}$ at $180 \mathrm{rpm}$ overnight. $50 \mathrm{~mL}$ buffered YNB-xylose was inoculated with the pre-culture to a starting $\mathrm{OD}_{620}$ of 0.05 , in a $250 \mathrm{~mL}$ baffled shake flask. The cultures were grown at $30^{\circ} \mathrm{C}$ at $180 \mathrm{rpm}$ for at least 82 hours. Optical density during growth was monitored at $620 \mathrm{~nm}$ using an Ultrospec 2100 Pro spectrophotometer (Amersham Biosciences Corp., USA). Samples were extracted for PHB quantification, $\mathrm{OD}_{620}$, cell dry weight measurements, and metabolite analysis, and were done in technical duplicates. Maximum specific growth rate was calculated by the analysis of the exponential growth phase, using a linear regression of the natural logarithm derived from the $\mathrm{OD}_{620}$.

For the experiments in bioreactors, unbuffered YNBxylose (13.4 $\mathrm{g} \mathrm{L}^{-1}$ Yeast nitrogen base, $50 \mathrm{~g} \mathrm{~L}^{-1}$ xylose) was used as media. Well-controlled Multifors $1.2 \mathrm{~L}$ vessels (Infors, Switzerland) were sparged with $1.0 \mathrm{vvm}$ air at $30^{\circ} \mathrm{C}$ and $300 \mathrm{rpm}$. A culture volume of $300 \mathrm{~mL}$ was inoculated with YNB-xylose freshly grown cells to a

Table 2 Primers used in the present study

\begin{tabular}{|c|c|c|}
\hline Name & Amplification target & Sequence $\left(5^{\prime}\right.$ to $\left.3^{\prime}\right)$ \\
\hline TEF1p_f & \multirow{2}{*}{ S. cerevisiae TEF1 promoter } & CTAGAGGATCCCCGGGTATAGCTTCAAAATGTTTCTAC \\
\hline TEF1p_r & & CACGTCAGTCATTTTGTAATTAAAACTTAGATTAG \\
\hline PhaA_f & \multirow{2}{*}{ Codon optimized PhaA ORF from C. necator } & GTITAATTACAAAATGACTGACGTGGTGATTG \\
\hline PhaA_r & & CACGTCAGTCATTTTGTAATTAAAACTTAGATTAGATTG \\
\hline TEF1t_f & \multirow{2}{*}{ S. cerevisiae TEF1 terminator } & GTTGAAAGAAAGTAAGGAGATTGATAAGACTTITC \\
\hline TEF1t_r & & GATATAGAGCTCAGATAGCGCCGATCAAAG \\
\hline TPI1p_f & \multirow{2}{*}{ S. cerevisiae TPI1 promoter } & TCTGAGCTCTATATCTAGGAACCCATCAG \\
\hline TPI1p_r & & CAATCCTITGCGTCATTITAAGTTATGTATGTGTITITG \\
\hline PhaB1_f & \multirow{2}{*}{ Codon optimized PhaB1 ORF from C. necator } & CATACATAAACTAAAAATGACGCAAAGGATTGCGTATG \\
\hline PhaB1_r & & GATAATATTITTATATAATTATATTATTAACCCATGTGTAAGCCAC \\
\hline TPI1t_f & \multirow{2}{*}{ S. cerevisiae TP/1 terminator } & CACATGGGTTAATAATATAATTATATAAAAATATTATCTTCTITC \\
\hline TPI1t_r & & CTAACTAGTTATATAACAGTTGAAATTTGGATAAG \\
\hline GPM1P_f & \multirow{2}{*}{ S. cerevisiae GPM1 promoter } & TATATAACTAGTTAGTCGTGCAATGTATGAC \\
\hline GPM1p_r & & CTTTACCAGTGGCCATTATTGTAATATGTGTGTTGTTTG \\
\hline PhaC1_f & \multirow{2}{*}{ Codon optimized PhaC1 ORF from C. necator } & CATATTACAATAATGGCCACTGGTAAAGG \\
\hline PhaC1_r & & CATTCATTCTTCAGACTTATGCCTITGCTITCACATAC \\
\hline GPM1t_f & \multirow{2}{*}{ S. cerevisiae GPM1 terminator } & GAAAGCAAAGGCATAAGTCTGAAGAATGAATGATTTG \\
\hline GPM1t_r & & TACCGCATCAGGCGCCATATTCGAACTGCCCATTCAG \\
\hline
\end{tabular}


starting $\mathrm{OD}_{620}$ of 0.05 . Silicon antifoam RD emulsion (Dow Corning, USA), $3 \mathrm{M} \mathrm{KOH}$ and $3 \mathrm{M} \mathrm{H}_{2} \mathrm{SO}_{4}$ were added as needed in order to avoid the excess of foaming and to keep the $\mathrm{pH}$ at 5.5, respectively. Two independent biological replicates were performed for each condition.

\section{Analysis of biomass and metabolites}

Cell dry weight was measured in triplicate by filtering a known volume (3.0 to $5.0 \mathrm{~mL}$ ) of the culture through a pre-weighed nitrocellulose filter with $0.45 \mu \mathrm{m}$ pore size (PALL, USA). The filters were washed, dried and weighed after equilibrating to room temperature in a desiccator. Biomass was correlated to $\mathrm{OD}_{620}$ by a single point calibration, based on the final measuring time point. Concentrations of glucose, xylose, xylitol, glycerol, acetate and ethanol were analyzed by HPLC (Waters, USA). Metabolites were separated using an Aminex HPX-87H ion exchange column (Bio-Rad, USA) at $45^{\circ} \mathrm{C}$ with $5 \mathrm{mM} \mathrm{H}_{2} \mathrm{SO}_{4}$ as mobile phase, at a flow rate of $0.6 \mathrm{~mL} \mathrm{~min}^{-1}$. All compounds were detected with a RID-10A refractive index detector (Shimadzu, Japan). Concentrations of metabolites were calculated from an external seven-point standard calibration curve. Samples were analyzed in technical duplicates.

\section{PHB quantification}

The method used relied on the quantitative conversion of PHB to crotonic acid catalyzed by hot concentrated sulfuric acid (Law and Slepecky 1961). A culture volume of 0.5 or $1.0 \mathrm{~mL}$ was harvested and transferred to a $1.5 \mathrm{~mL}$ microcentrifuge tube. The harvested cells were centrifuged for $5 \mathrm{~min}$ at $6000 \times g$ and the supernatant was discarded by careful aspiration (FTA-1, Biosan, Latvia). The pellet was washed with $1.0 \mathrm{~mL}$ ultrapure $\mathrm{H}_{2} \mathrm{O}$ and resuspended by vortexing, centrifuged for $5 \mathrm{~min}$ at $6000 \times g$ and the supernatant was discarded. This wash step was repeated two times. $\mathrm{H}_{2} \mathrm{SO}_{4}(0.5 \mathrm{~mL}$, $96 \% \mathrm{v} / \mathrm{v})$ was added to the pellet. The pellet was resuspended by careful pipetting, and the open-lid tubes were transferred to a heat block (Grant QBD1, Grant Instruments, UK), and incubated at $95^{\circ} \mathrm{C}$ for $1 \mathrm{~h}$. The resulting solution was diluted 20 times by a serial dilution and further analyzed by HPLC, using the same conditions as for the analysis of metabolites, and quantified by comparing to an external calibration curve of crotonic acid. Commercially available PHB (\#363502, Sigma-Aldrich) was used as method control and was processed similarly as pelletized cells. Samples were analyzed in technical duplicates.

\section{Results}

Construction of the expression vector carrying the PHB pathway genes

The $C$. necator PHB pathway, consisting of a $\beta$-ketothiolase (acetyl-CoA acetyltransferase) (encoded by $P h a A$ ), an acetoacetyl-CoA reductase (encoded by PhaB1), and a PHB synthase (encoded by PhaC1) (Figure 1A), was chosen for PHB production in S. cerevisiae as it has been successfully used in the past (see e.g. (Carlson and Srienc 2006;

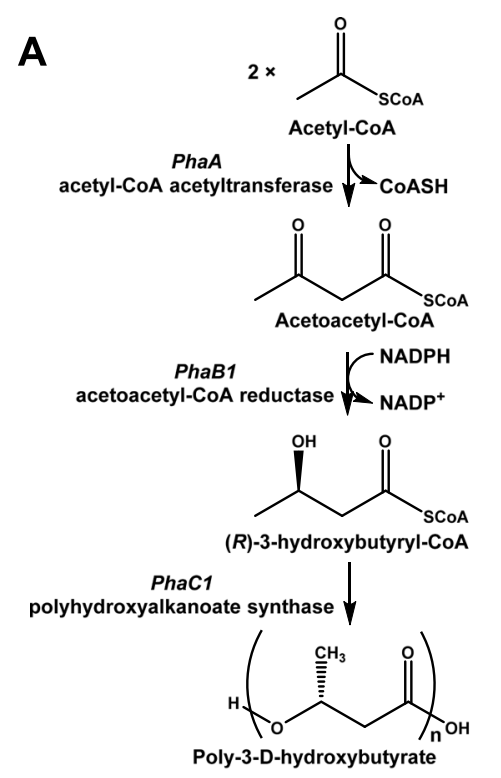

B

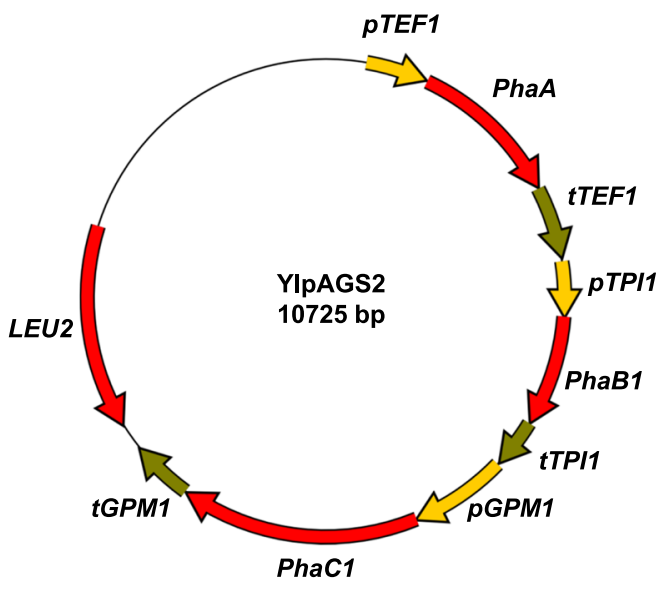

Figure 1 The PHB metabolic pathway, consisting of A) metabolite structures, involved enzymes, cofactors and B) the genes and regulatory sequences in the integrative vector YIpAGS2 in a schematic representation. 
Kocharin et al. 2012; Breuer et al. 2002)). The genes, ordered from MWG Eurofins, were codon optimized for $S$. cerevisiae, which notably led to lower GC-content (47-52\% GC) than the native bacterial genes (63-68\% GC). All three genes were cloned behind a strong constitutive promoter (pTEF1, pTPI1 and pGPM1 for PhaA, PhaB1 and PhaC1, respectively) into a single large vector, named YIpAGS2 (Figure 1B), based on YIplac128 which has a LEU2 gene for complementation of auxotrophic strains. The entire pathway was sequenced and validated.

\section{Strain engineering}

S. cerevisiae strain TMB 3043 (Karhumaa et al. 2005), that has been engineered for increased flux from xylulose to glycolysis, through the overexpression of xylulokinase and the non-oxidative pentose phosphate pathway genes, was transformed with YIpOB8 carrying the Scheffersomyces stipitis xylose genes encoding xylose reductase (XR) and xylitol dehydrogenase (XDH) (Bengtsson et al. 2009), generating strain TMB 4440.
TMB 4440 was further transformed with the constructed linearized YIpAGS2 that carries C. necator PHB pathway gene or with a linearized integrative control vector (YIplac128), generating strains TMB 4443 (PHB+) and TMB 4444 (PHB-), respectively.

\section{Evaluation of PHB production from xylose}

The generated strains were compared aerobically in well-stirred baffled flasks to evaluate their PHB production capacity. The strains were grown with D-xylose as sole carbon source, until the cultures reached late stationary phase. Metabolites were analyzed and cell dry weight calculated. Representative growth plots for the control strain TMB 4444 and the TMB 4443 strain expressing the $\mathrm{PHB}$ pathway genes are displayed in Figure $2 \mathrm{~A}$ and $2 \mathrm{~B}$, respectively.

As expected, both strains were able to grow on xylose. Xylitol, acetate and ethanol were the main by-products (Table 3). However strain TMB $4443(\mathrm{PHB}+)$ generated



B

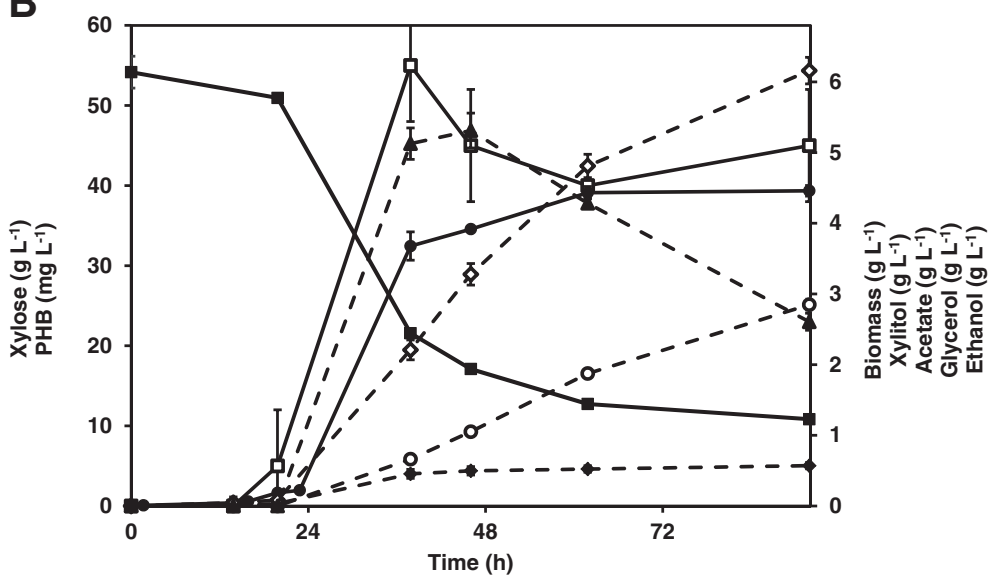

Figure 2 Representative aerobic growth and metabolite profiles from recombinant S. cerevisiae strains A) TMB 4444 (Control strain, PHB-) and B) TMB 4443 (PHB+), with xylose defined medium in buffered shake flask cultures. Legend: xylose( $\mathbf{m})$; biomass( $\bullet)$; glycerol( $\bullet)$; ethanol $(\boldsymbol{\Delta})$; $\mathrm{PHB}(\square)$; $x y l i t o l(0)$; acetate $(\diamond)$. 
Table 3 Physiological results of the strains grown aerobically on xylose on shake flasks or bioreactors

\begin{tabular}{|c|c|c|c|c|c|c|c|c|c|c|c|}
\hline \multirow[t]{2}{*}{ Strain } & \multirow{2}{*}{$\begin{array}{l}\text { Growth } \\
\text { condition }\end{array}$} & \multirow{2}{*}{$\begin{array}{l}\text { Growth rate } \\
\mu_{\max }\left(\mathrm{h}^{-1}\right)\end{array}$} & \multicolumn{6}{|l|}{ Yields } & \multirow{2}{*}{$\begin{array}{l}\text { PHB titer } \\
\text { (mg/L) }\end{array}$} & \multirow{2}{*}{$\begin{array}{l}\text { Final PHB } \\
\text { content } \\
(\% \text { CDW })\end{array}$} & \multirow{2}{*}{$\begin{array}{l}\text { Xylose/sugars } \\
\text { consumed (\%) }\end{array}$} \\
\hline & & & $\begin{array}{l}Y_{s x} \\
(g / g X y l)\end{array}$ & $\begin{array}{l}Y_{\text {sEtOH }} \\
\text { (g/g Xyl) }\end{array}$ & $\begin{array}{l}Y_{\text {sAc }} \\
\text { (g/g Xyl) }\end{array}$ & $\begin{array}{l}Y_{\text {sXylitol }} \\
\text { (g/g Xyl) }\end{array}$ & $\begin{array}{l}\text { sGly } \mathrm{Xyl} \text { (g/g Xyl) }\end{array}$ & $\begin{array}{l}Y_{\text {sPHB }} \\
\text { (mg/g Xyl) }\end{array}$ & & & \\
\hline 34443 & ake flask & $0.231=$ & $0.11 \pm 0.02$ & $0.10 \pm 0.05$ & $0.14 \pm 0.0$ & $0.05 \pm 0.03$ & $0.01 \pm 0.0$ & $1.17 \pm 0.18$ & $45.0 \pm 3.54$ & .03 & 76 \\
\hline 144 & ask & $0.249 \pm 0.01$ & 0.0 & 0.0 & $0.14 \pm 0.0$ & 0.10 & $0.02 \pm 0.0$ & $0.0 \pm$ & $0.0 \pm 0.0$ & 0.0 & $80.1 \pm 3.0$ \\
\hline MB 4443 & Bioreactor & $0.184 \pm 0.01$ & $0.41 \pm 0.02$ & $0.004 \pm 0.0$ & $0.0 \pm 0.0$ & $0.028 \pm 0.0$ & $0.0 \pm 0.0$ & $1.99 \pm 0.15$ & $101.7 \pm 7.1$ & $0.49 \pm 0.06$ & $100 \pm 0$ \\
\hline
\end{tabular}

The values reported are calculated for aerobic cultivations on defined media with xylose $\left(50 \mathrm{~g} \mathrm{~L}^{-1}\right)$ as carbon source. The specific growth rate is calculated for the exponential phase. Yields and titers are calculated from a single time point in the early stationary phase. Reported values represent the mean \pm SD of at least two independent cultivations performed. $Y_{s x}$ : biomass yield on xylose, $Y_{s E t O H}$ : yield of ethanol on xylose, $Y_{s A c}$ : yield of acetate on xylose, $Y_{s x y l i t o l}$ : yield of $x y l i t o l$ on xylose, $\mathrm{Y}_{\mathrm{sGly}}$ : yield of glycerol on xylose, $\mathrm{Y}_{\mathrm{sPHB}}$ : yield of PHB on xylose. PHB titer: The volumetric PHB titer. PHB/CDW: The PHB component as percentage of total cell dry weight.

less biomass and xylitol and more ethanol than the control strain TMB 4444. This was accompanied by PHB production that appeared to be concomitant with biomass formation. In the early exponential phase, PHB content rose more rapidly than the biomass titers under these shake flask conditions (Figure 2B). PHB yield peaked at $1.17 \pm 0.33 \mathrm{mg}$ PHB $\mathrm{g}^{-1}$ xylose consumed (Table 3) at the end of the exponential phase and further ethanol consumption did not result in additional PHB accumulation (Figure 2B).

As acetate levels were high and xylose utilization stopped before depletion, PHB production was also evaluated in another set-up using well-aerated and $\mathrm{pH}-$ controlled bioreactor for strain TMB 4443 (PHB+). Under these conditions, full xylose consumption was observed within 48 hours (Figure 3) and biomass accumulation was very high in comparison to the shake flask-experiments. Also, acetate, ethanol and xylitol production was significantly reduced. At the end of the exponential phase (48 hours), maximum biomass accumulation was reached and cellular PHB reached $0.49 \pm$ $0.06 \% \mathrm{PHB} / \mathrm{CDW}$, corresponding to a PHB yield of $1.99 \pm 0.15 \mathrm{mg} \mathrm{PHB} \mathrm{g}^{-1}$ xylose (Figure 3, Table 3).

\section{Discussion}

In the present study, PHB production from xylose was demonstrated using recombinant Saccharomyces cerevisiae. PHB production occurred under exponential growth phase, concomitant with the accumulation of ethanol and other by-products. The maximal PHB yield from xylose $\left(1.99 \pm 0.15 \mathrm{mg}\right.$ PHB g $\mathrm{g}^{-1}$ xylose, or 2.79 Cmmol PHB $\mathrm{Cmol}^{-1}$ xylose), that was achieved in wellaerated bioreactors, was comparable to reported nonxylose engineered strains harboring equivalent $C$. necator PHB pathways growing on glucose (Table 4), thereby demonstrating the potential of using a pentose carbon source, and more generally $\mathrm{C} 5$-rich lignocellulosic substrates for PHB production. One of the possible reasons might be

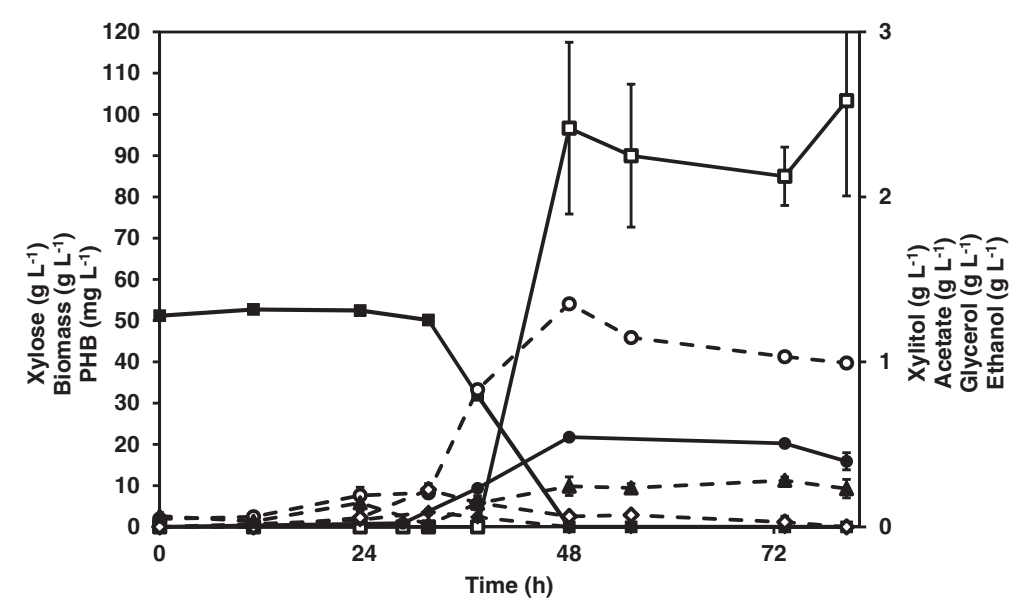

Figure 3 Representative fully aerobic batch growth and metabolite profile from recombinant $S$. cerevisiae strain TMB 4443 (PHB+) in xylose defined medium at $\mathbf{p H} 5.5$ using a well-controlled bioreactor. Legend: $x y l o s e(\mathbf{\bullet}) ; \operatorname{biomass}(\bullet) ; \operatorname{glycerol}(\bullet) ; \operatorname{ethanol}(\mathbf{\Delta}) ; \operatorname{PHB}(\square)$; xylitol(o); acetate( () . 
Table 4 Comparison of selected PHB producing S. cerevisiae strains harbouring the C. necator PHB pathway, consuming different carbon sources

\begin{tabular}{|c|c|c|c|c|c|c|c|}
\hline \multirow[t]{2}{*}{ Strain } & \multirow[t]{2}{*}{ Genotype } & \multirow[t]{2}{*}{ Carbon source } & \multirow[t]{2}{*}{$\begin{array}{l}\text { Growth } \\
\text { conditions }\end{array}$} & \multicolumn{2}{|c|}{$\begin{array}{l}\text { PHB yield/carbon } \\
\text { source }\end{array}$} & \multirow[t]{2}{*}{$\begin{array}{l}\text { PHB content } \\
\text { (mg/g CDW) }\end{array}$} & \multirow[t]{2}{*}{ Reference } \\
\hline & & & & $(\mathrm{mg} / \mathrm{g})$ & $(\mathrm{Cmmol} / \mathrm{Cmol})$ & & \\
\hline SCKK005 & PHB pathway & Glucose & Shake flask & $\sim 1.5^{\mathrm{a}}$ & $2.1^{\mathrm{a}}$ & 4.02 & (Kocharin et al. 2013) \\
\hline SCKO06 & $\begin{array}{l}\text { PHB pathway, }, \text { ADH2, } \\
\text { ALD6, acs }{ }^{\mathrm{L} 641 P}, \text { ERG10 }\end{array}$ & Glucose & Shake flask & $\sim 5^{\mathrm{a}}$ & $7^{\mathrm{a}}$ & 15.89 & (Kocharin et al. 2013) \\
\hline SCK032 & $\begin{array}{l}\text { PHB pathway, xpkA, } \\
a_{c k} \text { acs }{ }^{\mathrm{L} 641 \mathrm{P}}\end{array}$ & Glucose & Shake flask & $\sim 9^{\mathrm{a}}$ & $12.5^{\mathrm{a}}$ & 27.86 & (Kocharin et al. 2013) \\
\hline SCK034 & $\begin{array}{l}\text { PHB pathway, gapN, } \\
\text { ADH2, ALD6, acs }{ }^{\mathrm{L} 641 \mathrm{P}}, \text { ERG10 }\end{array}$ & Glucose & Shake flask & $\sim 7^{\mathrm{a}}$ & $9.8^{\mathrm{a}}$ & 27.52 & (Kocharin et al. 2013) \\
\hline SCKK006 & $\begin{array}{l}\text { PHB pathway, } A D H 2, \\
A L D 6, a^{L 641 P}, E R G 10\end{array}$ & Glucose & $\begin{array}{l}\text { Aerobic, chemostat } \\
\text { bioreactor, dilution } \\
\text { rate } 0.10 \mathrm{~h}^{-1}\end{array}$ & 2.79 & 3.67 & 5.59 & (Kocharin and Nielsen 2013) \\
\hline $\begin{array}{l}\text { Strain } \\
\text { RKS }\end{array}$ & $\begin{array}{l}\text { GAL1-10-induced PHB } \\
\text { pathway }\end{array}$ & Galactose/Glucose & $\begin{array}{l}\text { Aerobic, batch } \\
\text { bioreactor }\end{array}$ & $13.5^{\mathrm{b}}$ & $18.8^{\mathrm{b}}$ & 75 & (Carlson and Srienc 2006) \\
\hline TMB4443 & $\begin{array}{l}\text { PHB Pathway, XYL1, } \\
X Y L 2, X K S, P P P \uparrow, \text { gre3 }\end{array}$ & Xylose & Shake flask & 1.17 & 1.63 & 10.4 & This study \\
\hline TMB4443 & $\begin{array}{l}\text { PHB Pathway, } X Y L 1, \\
X Y L 2, X K S, P P P \uparrow, \text { gre } 3 \triangle\end{array}$ & Xylose & $\begin{array}{l}\text { Aerobic, batch } \\
\text { bioreactor }\end{array}$ & 1.99 & 2.79 & 4.9 & This study \\
\hline
\end{tabular}

a) Recalculated from graph presented in the respective references, based on total consumption of carbon sources.

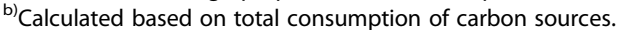

that xylose conversion to pyruvate does not involve the oxidative pentose phosphate pathway that is the main source of NADPH inside the cell (Bruinenberg et al. 1983). As a consequence more carbon may be diverted towards the $\mathrm{NADP}^{+}$-catalyzed formation of acetate that is a direct precursor for PHB synthesis.
The final titer reached a total of $45.0 \pm 3.5 \mathrm{mg} \mathrm{L}^{-1}$ of PHB for TMB $4443(\mathrm{PHB}+)$ in shake flask conditions, and increased to $101.7 \pm 7.1 \mathrm{mg} \mathrm{L}^{-1}$ of PHB in wellaerated bioreactor. By-product accumulation was much lower in the fully aerobic and $\mathrm{pH}$-controlled bioreactor set-up than in the shake-flask experiment,

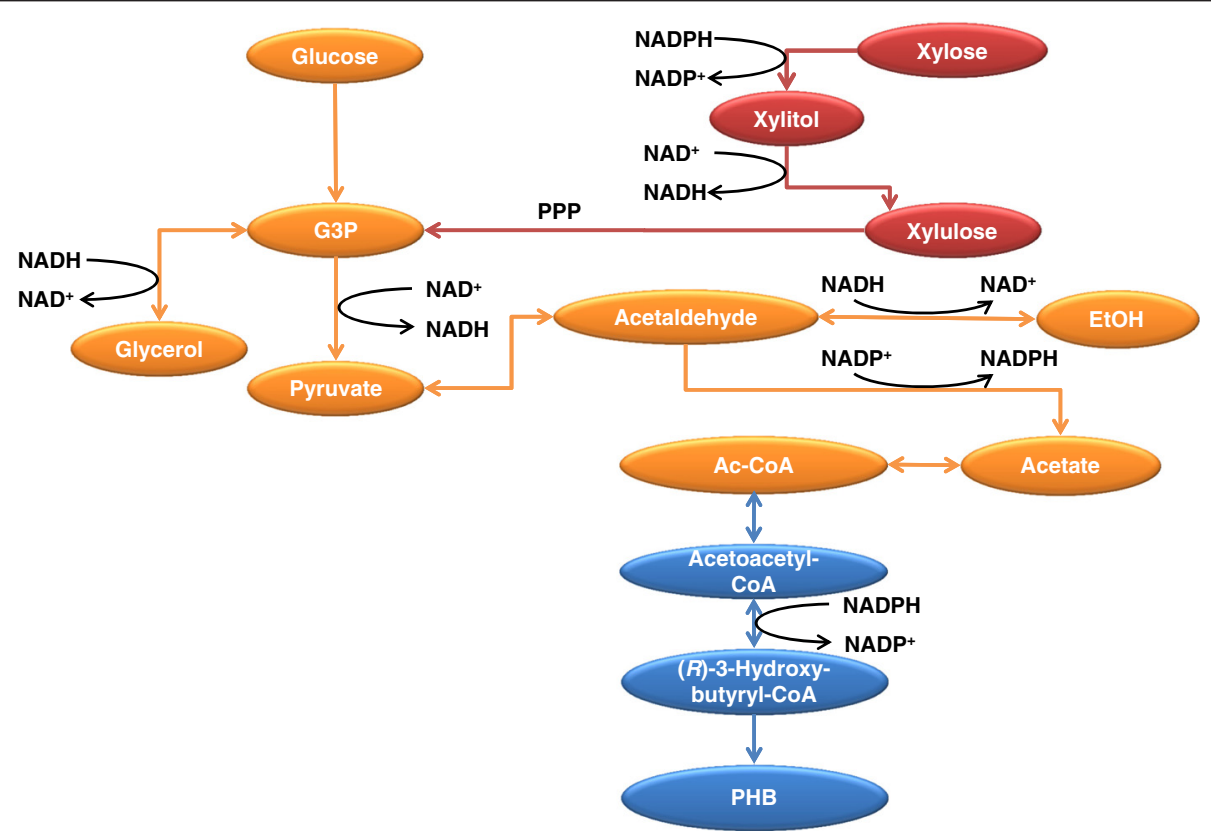

Figure 4 A condensed view of the glycolytic pathway steps, as well as the XR and PHB pathway steps that are relevant for the PHB accumulation in the constructed strain. Abbreviations: EtOH, ethanol; Ac-CoA, acetyl coenzyme A; G3P, glyceraldehyde 3-phosphate; PPP, pentose phosphate pathway The parts marked in red are the introduced xylose assimilation pathway and the overexpressed PPP. The parts marked in blue are the components of the PHB metabolic pathway. 
indicating increased respiratory metabolism that directly translated into higher biomass. This may explain the positive impact on PHB production as more cells were available to synthesize $\mathrm{PHB}$ while less carbon was dissipated into reduced byproducts. This observation was made despite the fact that low levels of acetate, that is required for PHB production (Figure 4), were generated. In contrast, unusually high $\mathrm{NADP}^{+}$-catalyzed acetate levels were observed in the shake flask experiments. In that case, the limited respiration may trigger higher availability of acetaldehyde precursor; this, combined with the need for additional routes for $\mathrm{NADPH}$ generation for biomass synthesis and for $\mathrm{xy}$ lose utilization via the NAD $(\mathrm{P}) \mathrm{H}$-dependent xylose reductase, could explain the dramatic increase in acetate production. It may also explain why xylose consumption stopped before completion as $\mathrm{pH}$ decreased over time (data not shown). The accumulation of acetate also indicates that, under these conditions, PHB generation may rather be controlled by reactions downstream of acetate (Figure 4). This includes the acetylCoA synthesis that has been shown to be limited by the availability of ATP and by the efficiency of the acetyl-CoA synthetase (Shiba et al. 2007), or the acetoacetyl-CoA reductase-catalyzed reduction that could be limited by NADPH shortage. Overall, the results indicate that a threshold in oxygenation may be necessary to provide sufficient resources for biomass synthesis while enabling sufficient formation and further conversion of the acetate precursor.

In this report PHB production from xylose was demonstrated in S. cerevisiae. Our results also point towards the importance of aeration on the synthesis of the PHB pathway precursor and cofactors. To further enhance the PHB accumulation process aspects such as redox balance and the acetyl-CoA node have to be considered.

\section{Abbreviations}

Acetyl-CoA: Acetyl coenzyme A; NAD ${ }^{+} / \mathrm{H}$ : Nicotinamide adenine dinucleotide; $\mathrm{NADP}^{+} / \mathrm{H}$ : Nicotinamide adenine dinucleotide phosphate; PCR: Polymerase chain reaction; OE-PCR: Overlap extension PCR; XR: Xylose reductase.

\section{Competing interests}

The authors declare that they have no competing interests.

\section{Authors' contributions \\ AGS participated in the design of the study and its coordination, carried out molecular genetic engineering, strain constructions and drafted the manuscript. AMH carried out molecular genetic engineering and strain constructions. DPN carried out all the growth assays, bioreactor experiments and HPLC method optimization and metabolite analysis. MGG conceived the study, participated in the design of the study and its coordination and helped to draft the manuscript. All authors read and approved the final manuscript.}

\section{Acknowledgements}

We would like to thank Nathasha Rizza, Henrik Almqvist, Gunnar Lidén, Basti Bergdahl, Ed van Niel, Biotrend S.A. and SilicoLife Lda for valuable input. The EU Commission (FP7 project BRIGIT, Contract nr 311935) is acknowledged for their financial support.
Received: 5 December 2014 Accepted: 26 January 2015

Published online: 25 February 2015

\section{References}

Bengtsson O, Hahn-Hägerdal B, Gorwa-Grauslund MF (2009) Xylose reductase from Pichia stipitis with altered coenzyme preference improves ethanolic xylose fermentation by recombinant Saccharomyces cerevisiae. Biotechnol Biofuels 2. doi:910.1186/1754-6834-2-9

Breuer U, Terentiev Y, Kunze G, Babel W (2002) Yeasts as producers of polyhydroxyalkanoates: genetic engineering of Saccharomyces cerevisiae. Macromol Biosci 2(8):380-386. doi:10.1002/1616-5195(200211)2:8<380::aidmabi380>3.0.co; $2-x$

Bruinenberg PM, Vandijken JP, Scheffers WA (1983) A theoretical analysis of NADPH production and consumption in yeasts. J Gen Microbiol 129 (APR):953-964

Carlson R, Srienc F (2006) Effects of recombinant precursor pathway variations on poly [(R)-3-hydroxybutyrate] synthesis in Saccharomyces cerevisiae. J Biotechnol 124(3):561-573. doi:10.1016/j.jbiotec.2006.01.035

Demeke MM, Dietz H, Li Y, Foulquie-Moreno MR, Mutturi S, Deprez S, Den Abt T, Bonini BM, Liden G, Dumortier F, Verplaetse A, Boles E, Thevelein JM (2013) Development of a D-xylose fermenting and inhibitor tolerant industrial Saccharomyces cerevisiae strain with high performance in lignocellulose hydrolysates using metabolic and evolutionary engineering. Biotechnol Biofuels 6(1):89, 1754-6834-6-89 [pii] 10.1186/1754-6834-6-89

European Parliament CotEU (2009) Promotion of the use of energy from renewable sources. http://eur-lex.europa.eu/legal-content/EN/ALL/? uri=CELEX:32009L0028

Foley JA, Ramankutty N, Brauman KA, Cassidy ES, Gerber JS, Johnston M, Mueller ND, O'Connell C, Ray DK, West PC, Balzer C, Bennett EM, Carpenter SR, Hill J, Monfreda C, Polasky S, Rockström J, Sheehan J, Siebert S, Tilman D, Zaks DP (2011) Solutions for a cultivated planet. Nature 478(7369):337-342. doi:10.1038/nature10452

Gietz RD, Akio S (1988) New yeast-Escherichia coli shuttle vectors constructed with in vitro mutagenized yeast genes lacking six-base pair restriction sites. Gene 74(20):527-534

Gietz R, Schiestl R (2007) Quick and easy yeast transformation using the LiAc/SS carrier DNA/PEG method. Nat Protoc 2(1):35-37. doi:10.1038/nprot.2007.14

Gírio F, Fonseca C, Carvalheiro F, Duarte L, Marques S, Bogel-Lukasik R (2010) Hemicelluloses for fuel ethanol: a review. Bioresour Technol 101(13):4775-4800. doi:10.1016/j.biortech.2010.01.088

Hahn-Hägerdal B, Karhumaa K, Fonseca C, Spencer-Martins I, Gorwa-Grauslund MF (2007) Towards industrial pentose-fermenting yeast strains. Appl Microbiol Biotechnol 74(5):937-953. doi:10.1007/s00253-006-0827-2

Karhumaa K, Hahn-Hägerdal B, Gorwa-Grauslund MF (2005) Investigation of limiting metabolic steps in the utilization of xylose by recombinant Saccharomyces cerevisiae using metabolic engineering. Yeast 22(5):359-368. doi:10.1002/yea.1216

Kim S, Park Y-C, Jin Y-S, Seo J-H (2013) Strain engineering of Saccharomyces cerevisiae for enhanced xylose metabolism. Biotechnol Adv. doi:10.1016/j. biotechadv.2013.03.004

Kocharin K, Nielsen J (2013) Specific growth rate and substrate dependent polyhydroxybutyrate production in Saccharomyces cerevisiae. AMB Express 3(1):18. doi:10.1186/2191-0855-3-18

Kocharin K, Chen Y, Siewers V, Nielsen J (2012) Engineering of acetyl-CoA metabolism for the improved production of polyhydroxybutyrate in Saccharomyces cerevisiae. AMB Express 2(1):52. doi:10.1186/2191-0855-2-52

Kocharin K, Siewers V, Nielsen J (2013) Improved polyhydroxybutyrate production by Saccharomyces cerevisiae through the use of the phosphoketolase pathway. Biotechnol Bioeng. doi:10.1002/bit.24888

Lambert JG, Hall CAS, Balogh S, Gupta A, Arnold M (2014) Energy, EROI and quality of life. Energy Policy 64:153-167. doi:10.1016/j.enpol.2013.07.001

Law J, Slepecky R (1961) Assay of poly-beta-hydroxybutyric acid. J Bacteriol 82:33-36

Leaf T, Peterson M, Stoup S, Somers D, Srienc F (1996) Saccharomyces cerevisiae expressing bacterial polyhydroxybutyrate synthase produces poly-3hydroxybutyrate. Microbiology 142(Pt 5):1169-1180. doi:10.1099/13500872142-5-1169

Lian J, Si T, Nair NU, Zhao H (2014) Design and construction of acetyl-CoA overproducing Saccharomyces cerevisiae strains. Metab Eng 24:139-149. doi:10.1016/j.ymben.2014.05.010 
Madison LL, Huisman GC (1999) Metabolic engineering of poly(3hydroxyalkanoates): from DNA to plastic. Microbiol Mol Biol Rev: MMBR 63(1):21-53

Nijkamp JF, van den Broek M, Datema E, de Kok S, Bosman L, Luttik MA, Daran-Lapujade P, Vongsangnak W, Nielsen J, Heijne WH, Klaassen P, Paddon CJ, Platt D, Kötter P, van Ham RC, Reinders MJ, Pronk JT, de Ridder D, Daran J-MMC (2012) De novo sequencing, assembly and analysis of the genome of the laboratory strain Saccharomyces cerevisiae CEN.PK113-7D, a model for modern industrial biotechnology. Microb Cell Fact 11:36. doi:10.1186/14752859-11-36

Novy V, Krahulec S, Longus K, Klimacek M, Nidetzky B (2013) Co-fermentation of hexose and pentose sugars in a spent sulfite liquor matrix with genetically modified Saccharomyces cerevisiae. Bioresour Technol 130:439-448

Philip S, Keshavarz T, Roy I (2007) Polyhydroxyalkanoates: biodegradable polymers with a range of applications. J Chem Technol Biotechnol 82. doi:10.1002/jctb.1667

Poehlein A, Kusian B, Friedrich B, Daniel R, Bowien BC (2011) Complete genome sequence of the type strain Cupriavidus necator N-1. J Bacteriol 193(18):5017. doi:10.1128/jb.05660-11

Runquist D, Hahn-Hägerdal B, Bettiga M (2010) Increased ethanol productivity in xylose-utilizing Saccharomyces cerevisiae via a randomly mutagenized xylose reductase. Appl Environ Microbiol 76(23):7796-7802. doi:10.1128/aem. 01505-10

Shiba Y, Paradise EM, Kirby J, Ro DK, Keasing JD (2007) Engineering of the pyruvate dehydrogenase bypass in Saccharomyces cerevisiae for high-level production of isoprenoids. Metab Eng 9(2):160-168. doi:10.1016/j. ymben.2006.10.005

Sun J, Shao Z, Zhao H, Nair N, Wen F, Xu J-H, Zhao H (2012) Cloning and characterization of a panel of constitutive promoters for applications in pathway engineering in Saccharomyces cerevisiae. Biotechnol Bioeng 109(8):2082-2092. doi:10.1002/bit.24481

Suriyamongkol P, Weselake R, Narine S, Moloney M, Shah S (2007) Biotechnological approaches for the production of polyhydroxyalkanoates in microorganisms and plants - a review. Biotechnol Adv 25(2):148-175. doi:10.1016/j.biotechadv.2006.11.007

Vandamme P, Coenye T (2004) Taxonomy of the genus Cupriavidus: a tale of lost and found. Int J Syst Evol Microbiol 54(Pt 6):2285-2289. doi:10.1099/ijs. 0.63247-0

\section{Submit your manuscript to a SpringerOpen ${ }^{\circ}$ journal and benefit from:}

- Convenient online submission

- Rigorous peer review

- Immediate publication on acceptance

- Open access: articles freely available online

- High visibility within the field

- Retaining the copyright to your article 